Volume 2 Nomor. 2, Oktober 2017

P -ISSN : 2541-1179, E-ISSN : 2581-1711

OJS :http://journal.uin-alauddin.ac.id/index.php/instek/index

INFORIATIKASANS DAN TERNOLOG

Email : instek@uin-alauddin.ac.id

\title{
APLIKASI SMART TRASH CAN DALAM MENGATASI PERSOALAN SAMPAH SECARA MOBILE BERBASIS ANDROID
}

\author{
Faisal \\ Dosen Jurusan Teknik Informatika \\ Fakultas Sains \& Teknologi UIN Alauddin Makassar \\ E-mail : faisalrahman_ti_uin@yahoo.co.id
}

\begin{abstract}
ABSTRAK
Fokus kajian terkait penanganan sampah secara mobile dengan sistem Smart Trash Can berbasis android . Tujuan dari penelitian ini adalah merancang aplikasi Smart trash can dalam penanganan sampah secara mobile. Istilah Smart Trash Can diperuntukkan untuk tempat sampah yang mempunyai fitur dengan fungsi yang lebih dari tempat sampah pada umumnya. Perancangan sistem penanganan masalah sampah ini menggunakan Arduino UNO sebagai pengolah data, sensor berat dan sensor jarak sebagai parameter tempat sampah penuh. Hasil dari sensor tersebut kemudian dikirimkan ke web server untuk diolah dan dikirimkan ke smartphone android petugas kebersihan sebagai pemberitahuan untuk segera menangani tempat sampah yang telah penuh. Penelitian ini menggunakan metode penelitian kualitatif Design and Creation dan pengujian yang dilakukan adalah pengujian blackbox yang berfokus pada persyaratan fungsional perangkat lunak. Hasil dari penelitian ini adalah sebuah sistem smart trash can berbasis android. Fungsi sistem ini yaitu tempat sampah akan mengirimkan informasi berupa lokasi dan berat sampah apabila telah penuh agar segera ditangani.
\end{abstract}

Kata Kunci : Internet of Things, Smart Trash Can, Android, Arduino UNO

\section{I.PENDAHULUAN}

Sampah merupakan salah satu permasalahan kompleks yang dihadapi, baik oleh negara-negara berkembang maupun negara-negara maju di dunia. Permasalahan sampah akan semakin serius jika tidak segera menerapkan penanganan yang tepat. Kota Makassar merupakan salah satu kota yang sering kali disibukkan dengan masalah sampah, hal tersebut dibuktikan dengan banyaknya sampah yang berserakan di jantung kota dan tampak tidak ditangani dengan baik padahal pemerintah telah menempatkan tempat sampah pada hampir semua tepi jalan yang ada di kota Makassar. 
Volume 2 Nomor. 2, Oktober 2017

P-ISSN : 2541-1179, E-ISSN : 2581-1711

OJS :http://journal.uin-alauddin.ac.id/index.php/instek/index

Perkembangan teknologi juga menyentuh aspek kepedulian terhadap lingkungan dengan adanya tempat sampah pintar atau biasa disebut dengan Smart Trash Can . Tempat sampah yang dulunya mempunyai fungsi tunggal dengan menampung sampah saja kini telah dipadukan dengan teknologi dengan menambahkan fungsi tertentu. Baik berupa otomatisasi buka tutup pada tempat sampah sampai pengiriman informasi keadaan tempat sampah kepada petugas kebersihan sehingga lebih efisien karena tidak perlu menunggu laporan secara manual dari warga.

Tujuan dari perancangan adalah untuk merancang sebuah aplikasi Smart Trash Can yang diharapkan mampu menangani atau mengurangi persoalan sampah yang kerap terjadi di kota Makassar.

Berdasarkan latar belakang tersebut, peneliti ingin merancang suatu sistem berbasis Android yang mampu membantu pemerintah menangani masalah sampah dengan memberikan informasi kepada petugas yang bersangkutan terkait permasalahan tempat sampah yang bisa didapatkan langsung dari smartphone.

\section{METODOLOGI PENELITIAN}

\section{A. Jenis dan Lokasi Penelitian}

Dalam melakukan penelitian ini, jenis penelitian kualitatif yang digunakan adalah Simulation, Survei, Design and Creation. Lokasi penelitian ini dilakukan di beberapa titik tempat sampah dan bak sampah di kota Makassar, sedangkan perancangan alat dilakukan di laboratorium pemrograman Teknik Informatika UIN Alauddin Makassar.

\section{B. Instrumen Penelitian}

Instrument penelitian yang digunakan dalam penelitan yaitu :

\section{Perangkat Keras}

Perangkat keras yang digunakan untuk mengembangkan dan mengumpulkan data pada aplikasi ini adalah sebagai berikut:

a. Laptop ASUS A43S dengan spesifikasi :

1) Prosesor Intel ${ }^{\circledR}$ Core $^{\mathrm{TM}}$ i5 $(2.50 \mathrm{Ghz})$ 
Volume 2 Nomor. 2, Oktober 2017

P-ISSN : 2541-1179, E-ISSN : 2581-1711

OJS :http://journal.uin-alauddin.ac.id/index.php/instek/index

Email : instek@uin-alauddin.ac.id

2) Display 14" WXGA LED, Max. Resolution 1366 x 768

3) RAM 4 GB DDR3 Memory

4) Harddisk 500GB

b. Ponsel Xiaomi Redmi 1S dengan spesifikasi :

1) Android OS, v4.4 (Kitkat)

2) Qualcomm MSM8228 Snapdragon 400 Quad-core 1.6 GHz Cortex-A7

3) GPU Andreno 305

4) Resolusi $720 \times 1280$ pixels ( $\sim 312$ ppi pixel density)

5) Internal 8GB, 1 GB RAM 29

\section{Perangkat Lunak}

Adapun perangkat lunak yang digunakan dalam aplikasi ini adalah sebagai berikut :

a. Sistem Operasi Windows 7 Ultimate 64-bit.

b. Android Studio Versi 2.1.2

c. SDK

d. JDK

e. Web Server

f. SQLite Manager

g. Driver Arduino

h. Sistem Operasi Android

\section{Perancangan Sistem}

Untuk menjelaskan perancangan sistem yang dilakukan dalam mewujudkan penelitian sistem smart trash can berbasis Android dengan keluaran berupa sistem pengelolaan tempat sampah, terlebih dahulu secara umum digambarkan oleh blok diagram sistem kerja yang ditunjukkan. 
Volume 2 Nomor. 2, Oktober 2017

P -ISSN : 2541-1179, E-ISSN : 2581-1711

OJS :http://journal.uin-alauddin.ac.id/index.php/instek/index

Email : instek@uin-alauddin.ac.id

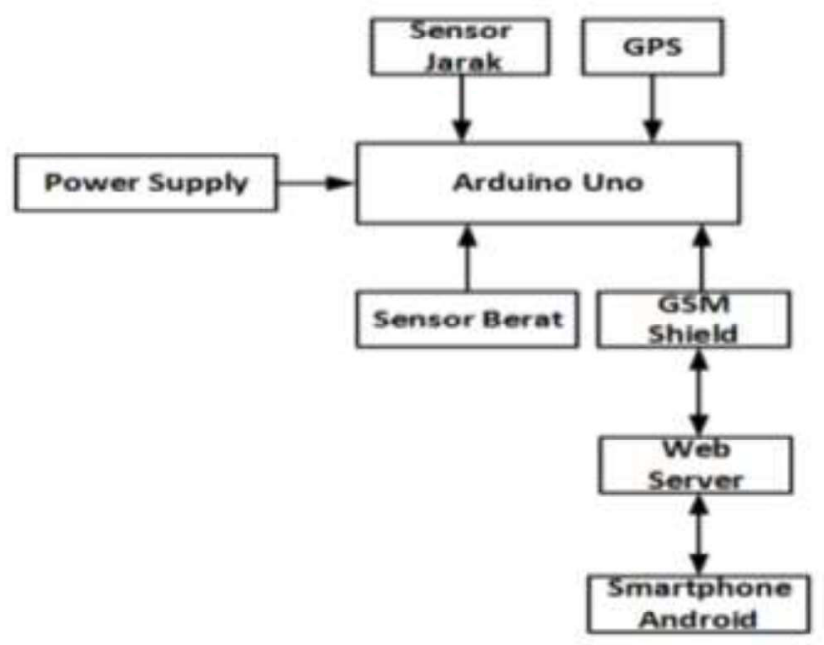

Gambar 1.Diagram blok Sistem Smart Trash Can berbasis Android Sensor

III. HASIL DAN PEMBAHASAN

A. Hasil Perancangan Perangkat Keras



Gambar 2 Hasil Rancangan Sistem Smart Trash Can berbasis android

B. Aplikasi Smartphone Android

\section{Antarmuka Splash Screen}

Splash Screen merupakan halaman pertama yang tampil saat user membuka aplikasi, setelah itu tampil halaman login. 
Volume 2 Nomor. 2, Oktober 2017

P-ISSN : 2541-1179, E-ISSN : 2581-1711

OJS :http://journal.uin-alauddin.ac.id/index.php/instek/index

Email : instek@uin-alauddin.ac.id

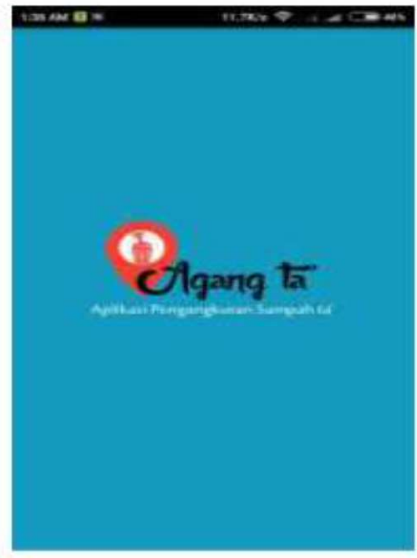

\section{Gambar 3. Tampilan Splash Screen}

\section{Antarmuka Menu Login}

Menu login merupakan halaman yang menampilkan form agar pengguna memasukkan username dan password. Jika data yang dimasukkan sesuai dengan database maka akan tampil menu utama.

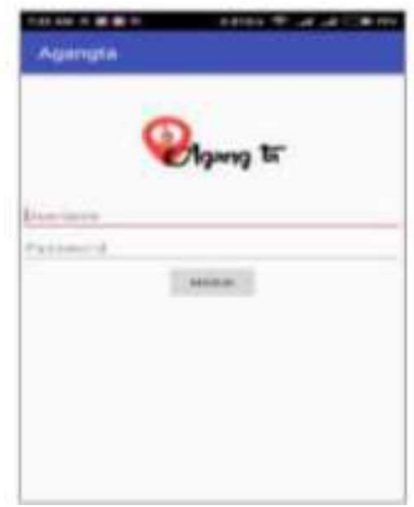

Gambar 4. Tampilan Menu Manajemen User

\section{Antarmuka Menu Utama}

Menu utama merupakan menu yang tampil setelah berhasil login dan pengguna bisa memilih menu yang diinginkan. 
Volume 2 Nomor. 2, Oktober 2017

P-ISSN : 2541-1179, E-ISSN : 2581-1711

OJS :http://journal.uin-alauddin.ac.id/index.php/instek/index

Email : instek@uin-alauddin.ac.id
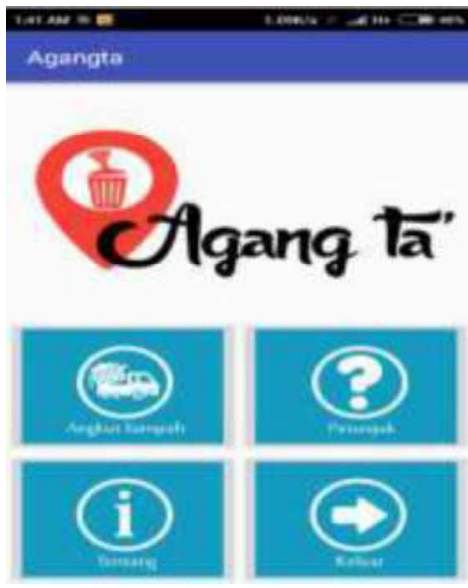

Gambar 5. Tampilan Menu Utama

\section{Antarmuka Menu Angkut Sampah}

Menu angkut sampah merupakan menu yang berfungsi agar pengguna dapat melihat status dan lokasi tempat sampah yang ada. Pada menu angkut sampah terdapat dua pilihan yaitu menampilkan daftar angkut dan menampilkan daftar lokasi.

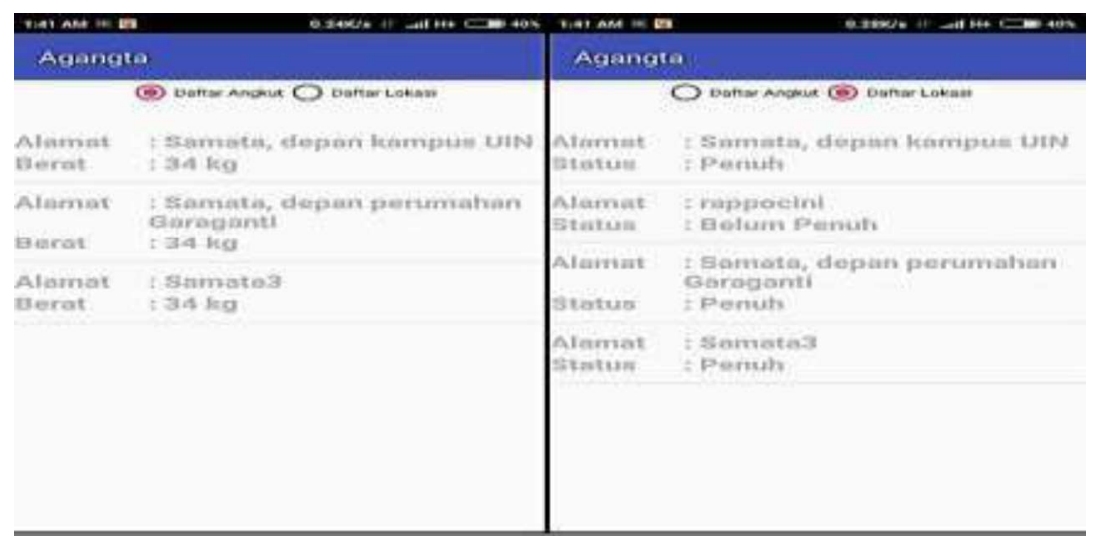

Gambar 6. Tampilan Menu Angkut Sampah 
Volume 2 Nomor. 2, Oktober 2017

P-ISSN : 2541-1179, E-ISSN : 2581-1711

OJS :http://journal.uin-alauddin.ac.id/index.php/instek/index

INFORMATKASANSOAN TERNOLOG

Email : instek@uin-alauddin.ac.id

\section{Hasil Pengujian Sistem}

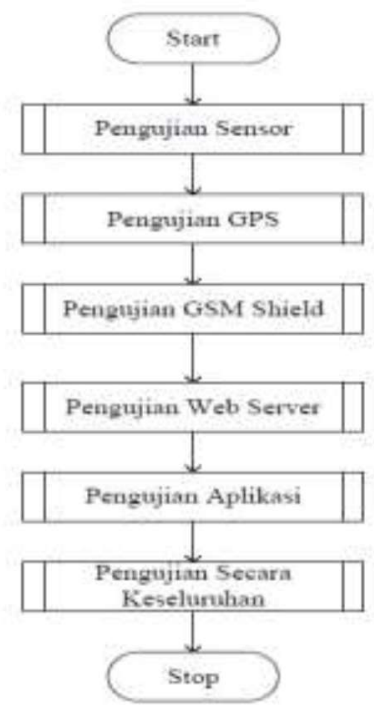

Gambar 7. Diagram hasil pengujian sistem

Pengujian sistem yang digunakan dalam penelitian ini adalah Black Box. Pengujian Black Box yaitu menguji perangkat dari segi spesifikasi fungsional tanpa menguji desain dan kode program. Pengujian dimaksudkan untuk mengetahui apakah fungsi-fungsi dan keluaran sudah berjalan sesuai dengan keinginan.

Tabel 1. Pengujian Sensor berat

\begin{tabular}{|c|c|r|c|}
\hline \multirow{2}{*}{ No. } & \multicolumn{2}{|c|}{ Pengujian sensor berat dengan } & \multirow{2}{*}{ Keterangan } \\
\cline { 2 - 3 } & Berat yang & Berat yang dideteksi & \\
\hline 1 & dimasukkan $(\mathrm{kg})$ & sensor $(\mathrm{kg})$ & Sesuai \\
2 & $1 \mathrm{~kg}$ & $1 \mathrm{~kg}$ & Sesuai \\
3 & $2 \mathrm{~kg}$ & $2 \mathrm{~kg}$ & Sesuai \\
\hline
\end{tabular}


Volume 2 Nomor. 2, Oktober 2017

P -ISSN : 2541-1179, E-ISSN : 2581-1711

OJS :http://journal.uin-alauddin.ac.id/index.php/instek/index

Email : instek@uin-alauddin.ac.id

Tabel 2. Pengujian Sensor Jarak

\begin{tabular}{|c|c|c|c|}
\hline \multirow{2}{*}{ No. } & \multicolumn{2}{|c|}{ Pengujian sensor jaxak } & \multirow{2}{*}{ Keterangan } \\
\cline { 2 - 3 } & Manual (cm) & $\begin{array}{c}\text { Menggumakan sensor } \\
(\mathrm{cm})\end{array}$ & \\
\hline 1 & $25 \mathrm{~cm}$ & $25 \mathrm{~cm}$ & Sesuai \\
2 & $14 \mathrm{~cm}$ & $14 \mathrm{~cm}$ & Sesuai \\
3 & $4 \mathrm{~cm}$ & $4 \mathrm{~cm}$ & Sesuai \\
\hline
\end{tabular}

Tabel 3. Pengujian Koordinat menggunakan modul GPS

\begin{tabular}{|c|c|c|}
\hline No. & Lokasi & Pengujian koordinat \\
& & Menggunakan modul GPS \\
\hline 1 & Perumahan Patri & $-5.205824,119.501673$ \\
2 & J1.Veteran Bakung & $-5.196888,119.498667$ \\
\hline
\end{tabular}

Tabel 4. Pengujian pengiriman menggunakan GSM Shiled

\begin{tabular}{|c|c|c|c|}
\hline \multirow{2}{*}{ No. } & \multicolumn{2}{|c|}{$\begin{array}{c}\text { Pengujian pengiriman menggunakan } \\
\text { Gerat penuh }\end{array}$} & \multirow{2}{*}{ Keterangan } \\
\cline { 2 - 4 } & $>=3(\mathrm{~kg})$ & $<4(\mathrm{~cm})$ & \\
\hline 1 & $1.50 \mathrm{~kg}$ & $6 \mathrm{~cm}$ & Tidak Mengirim \\
2 & $3.50 \mathrm{~kg}$ & $3.50 \mathrm{~cm}$ & Mengirim \\
3 & $4 \mathrm{~kg}$ & $4 \mathrm{~cm}$ & Mengirim \\
\hline
\end{tabular}

\section{Pembahasan Hasil Pengujian}

Pengujian sistem secara keseluruhan dimulai pada saat mikrokontroler Arduino UNO aktif. Fungsi perangkat yang terpasang pada Arduino UNO diuji mulai dari sensor yang digunakan. Sensor berat dan sensor jarak merupakan 
Volume 2 Nomor. 2, Oktober 2017

P-ISSN : 2541-1179, E-ISSN : 2581-1711

OJS :http://journal.uin-alauddin.ac.id/index.php/instek/index

Email : instek@uin-alauddin.ac.id

sensor utama sebagai parameter status penuh atau tidaknya tempat sampah. Kemudian status tempat sampah dan lokasi tempat sampah yang ditentukan oleh modul GPS dikirimkan menggunakan GSM Shield dengan memastikan lampu status network pada GSM Shield berkedapkedip menandakan stabilitas jaringan yang digunakan.

\section{IV.KESIMPULAN}

Berdasarkan hasil penelitian dan pembahasan maka dapat ditarik kesimpulan sebagai berikut:

- Sistem Smart Trash Can berbasis android terdiri dari mikrokontroler arduino UNO yang mengirimkan status tempat sampah ke web server kemudian diolah dan diteruskan ke smartphone android petugas kebersihan sehingga dapat memaksimalkan penanganan permasalahan sampah.

- Sistem dengan integrasi tempat sampah dan web server memungkinkan tempat sampah dapat dimonitoring.

- Perangkat dapat mengirimkan notifikasi kepada pengguna apabila tempat sampah telah penuh. 
Volume 2 Nomor. 2, Oktober 2017

P-ISSN : 2541-1179, E-ISSN : 2581-1711

OJS :http://journal.uin-alauddin.ac.id/index.php/instek/index

Email : instek@uin-alauddin.ac.id

\section{DAFTAR PUSTAKA}

Alex. Sukses Mengelola Sampah Organik Menjadi Pupuk Organik. Yogyakarta: Pustaka Baru Press, 2012

Jogiyanto, HM. Sistem Teknologi Informasi, Andi. Yogyakarta, 2001.

Jogiyanto, HM. Analisis dan Desain Sistem Informasi, Edisi III, Andi.

Yogyakarta,

2005.

Kreibich, J. A. Using SQLite. United State of America: O'Reilly Media, 2010.

Margolis, Michael. Arduino Cookbook. USA : O'Reilly Media, 2011

Mutardjo, Djuli dan Said, E.G. Penanganan dan Pemanfaatan Limbah Padat. Jakarta:Madyatama Sarana Perkasa, 1997.

Pressman, Roger S. Software Engineering: A Practitioner's Approach. Cet. 7; MHHE,2010.

Putra, Anna Arthdi. Android dan Anak Tukang Sayur. Lubuklinggau : wartechid.com, 2012.

Wahyudi dan Subandu. Sistem Informasi Manajemen. Yogyakarta: Gajah Mada University Press, 1996. 